\title{
Effect of Malaria and Fever on Energy Metabolism in Gambian Children
}

\author{
NICOLAS STETTLER, YVES SCHUTZ, ROGER WHITEHEAD, AND ERIC JÉQUIER \\ Institute of Physiology, Faculty of Medicine, University of Lausanne, 1005 Lausanne, Switzerland [N.S., Y.S., \\ E.J.] and Medical Research Council, Dunn Nutrition Unit, Keneba, The Gambia and Cambridge, \\ United Kingdom [R.W.]
}

\begin{abstract}
The aim of the present study was to measure the changes in resting energy expenditure (REE) induced by malaria and to assess to what extent they are related to fever and nutritional status. The REE of 19 Gambian children (mean age $\pm S E M, 9 \pm 1$ y; weight, $24 \pm 2 \mathrm{~kg}$; expected weight for height $86 \pm 1 \%$ ) were measured with a hood system at repeated intervals at the onset of malaria crisis (test A), 3 to $4 \mathrm{~d}$ after therapy (test B), and 14 to 21 d later (test $\mathrm{C}$ ). Axillary temperature averaged 39.2 \pm 0.1 , $36.6 \pm 0.1$, and $36.7 \pm 0.1^{\circ} \mathrm{C}$ in the tests $\mathrm{A}, \mathrm{B}$, and $\mathrm{C}$, respectively. REE in test $A$ was significantly higher than REE in test B $(223 \pm 10$ versus $174 \pm 8 \mathrm{~kJ} / \mathrm{kg} \cdot \mathrm{d}, p<$ $0.0001)$, but in test $C(169 \pm 8 \mathrm{~kJ} / \mathrm{kg} \cdot \mathrm{d})$, it did not differ from that observed in test $B$. The percentage of increase in REE was significantly correlated with the difference in axillary temperature $(r=0.46, p<0.05)$; the slope of the regression line indicated an increase of $6.9 \%$ in $\mathrm{REE} /{ }^{\circ} \mathrm{C}$ of fever. Furthermore, the individual increase in REE $/{ }^{\circ} \mathrm{C}$ was correlated to the percentage of weight for height of the children $(r=0.54, p<0.05)$, indicating that the child's nutritional status influences the magnitude of the hypermetabolism due to fever. We concluded that Gambian children suffering from an acute episode of malaria have an increase in REE averaging 30\%; however, REE promptly returns to baseline value a few days after the beginning of therapy. (Pediatr Res 31: 102-106, 1992)
\end{abstract}

\section{Abbreviations}

BMI, body mass index, adiposity index (weight/height ${ }^{2}$, i.e. $\mathrm{kg} / \mathrm{m}^{2}$ )

REE, resting energy expenditure

It has been well established that recurrent infections (diarrheal diseases, respiratory tract infections, malaria) are, together with chronic insufficient or marginal nutrient intake, one of the main causes of the failure to thrive in children living in developing countries $(1,2)$. Although the impact of infection on growth has been the object of a number of studies (3), there is little quantitative information about the energy cost of specific infections, and the extent to which episodes of infection lead to a specific change in energy requirements is largely unknown in children.

During frequent episodes of acute illness, the increase in energy expenditure combined with a low energy intake due to anorexia is an important factor explaining the poor growth commonly observed in many children from developing countries. Surpris-

Received February 19, 1991; accepted August 3, 1991.

Correspondence and reprint requests: Prof. E. Jéquier, Institute of Physiology, Faculty of Medicine, Rue du Bugnon 7, 1005 Lausanne, Switzerland.

Supported by the Nestle Foundation, Lausanne, Switzerland. ingly, Eccles et al. (4) showed a decrease in sleeping energy expenditure averaging $16 \%$ during episodes of malaria in children after correcting for the effect of body temperature, as compared with the period before the illness, whereas Duggan and coworkers (5-7) showed a negative energy balance but no increase in energy expenditure during measles in children. These results do not support the results of Du Bois (8), who showed an increase in energy expenditure that accompanies the fever episode.

These contradictory results have prompted us to assess the energy cost of an acute episode of malaria in Gambian children using indirect calorimetry. Another aim of the study was to investigate whether the changes in REE are related to the changes in body temperature, to nutritional state, or to parasitemia.

\section{SUBJECTS AND METHODS}

Environmental conditions. The study took place from October 1989 to September 1990 in Keneba, a rural village of the West Kiang district of The Gambia, West Africa. The life conditions of this village have been extensively described previously (9-11). During the rainy season (June to October), malaria is endemic with Plasmodium falciparum predominating. Because of the partial immunity of the children, most infections do not induce the well-known recurrent episodes of fever, but usually the symptomatology consists in a persistent fever with headaches, nausea, and vomiting. At that time of the year, the food available to the family is restricted because the previous year's food stores are almost exhausted.

Subjects (Table 1). Twelve girls and eight boys were recruited at the Keneba outpatient clinic to take part in the present study. Their acceptance to participate was obtained from their relatives after a detailed explanation of the procedure was given to them. The study did not interfere with the usual treatment of the children, which was immediately initiated after the diagnosis had been made. The study protocol was submitted to and approved by the Medical Research Council/Gambian Government Ethical Committee. One of the girls did not complete the study because she did not follow the treatment completely and, consequently, still had fever at the time of the second measurement.

Anthropometry. Body weight was measured immediately before the calorimetric measurements in fasting conditions with an accuracy of $0.1 \mathrm{~kg}$ (Kipfer scale, model DPW 150, Jegendorf, Switzerland), with the child dressed with a light African cloth.

The initial physical characteristics of each child are given in Table 1 . Body fat was assessed by measuring skinfold thickness at four different sites (biceps, triceps, subscapular, and suprailiac) (12) with a caliper (Holtain Ltd., Crymych, UK) allowing measurements with a precision of $\pm 0.2 \mathrm{~mm}$. The mean body fat, calculated using the equation of Brook (13), averaged $9.9 \pm 0.6 \%$ of total body weight, and the mean fat-free mass was $21.7 \pm 1.8$ $\mathrm{kg}$.

Experimental design. The children admitted to the Keneba 
Table 1. Physical characteristics

\begin{tabular}{|c|c|c|c|c|c|c|c|c|c|}
\hline Subject & Sex & $\begin{array}{c}\text { Age } \\
(\mathrm{y})\end{array}$ & $\begin{array}{c}\text { Weight A } \\
(\mathrm{kg})\end{array}$ & $\begin{array}{c}\text { Weight B } \\
(\mathrm{kg})\end{array}$ & $\begin{array}{c}\text { Weight C } \\
(\mathrm{kg})\end{array}$ & $\begin{array}{c}\text { Height } \\
(\mathrm{cm})\end{array}$ & $\begin{array}{c}\text { BMI } \\
\left(\mathrm{kg} / \mathrm{m}^{2}\right)\end{array}$ & $\begin{array}{l}\text { Weight for } \\
\text { height* } \\
(\%)\end{array}$ & $\begin{array}{l}\text { Parasites } \\
\text { (no. } / \mu \mathrm{L} \text { ) }\end{array}$ \\
\hline 1 & $\mathrm{~F}$ & 10.0 & 27.0 & 27.7 & 28.3 & 138.0 & 14.2 & 85.6 & 35400 \\
\hline 2 & $\mathrm{~F}$ & 12.4 & 26.2 & 25.5 & 25.7 & 144.0 & 12.6 & 70.9 & 30100 \\
\hline 3 & $\mathrm{M}$ & 15.0 & 43.8 & 44.2 & 46.1 & 163.5 & 16.4 & 86.3 & 818000 \\
\hline 4 & $\mathrm{~F}$ & 13.7 & 38.7 & 37.1 & 38.7 & 153.0 & 16.5 & 93.2 & 85200 \\
\hline 5 & $\mathrm{~F}$ & 3.7 & 12.1 & 12.2 & 12.4 & 94.5 & 13.5 & 85.7 & 69400 \\
\hline 6 & $\mathrm{~F}$ & 12.4 & 32.6 & 31.1 & 32.6 & 147.0 & 15.1 & 83.1 & 61400 \\
\hline 7 & $\mathrm{~F}$ & 5.8 & 15.7 & 15.9 & 15.8 & 109.0 & 13.2 & 87.5 & 60900 \\
\hline 8 & $\mathrm{~F}$ & 6.8 & 22.3 & 22.9 & 22.5 & 124.5 & 14.4 & 92.6 & 7880 \\
\hline 9 & $M$ & 7.0 & 17.9 & 18.3 & 19.2 & 116.0 & 13.3 & 86.3 & 9200 \\
\hline 10 & $\mathrm{~F}$ & 7.7 & 17.4 & 16.7 & 16.8 & 117.5 & 12.6 & 84.3 & 18100 \\
\hline 11 & $\mathrm{M}$ & 9.4 & 27.3 & 27.0 & 27.4 & 138.5 & 14.2 & 84.7 & 51400 \\
\hline 12 & $\mathrm{M}$ & 13.2 & 30.6 & 30.8 & 31.0 & 142.5 & 15.1 & 86.8 & 38000 \\
\hline 13 & $\mathrm{M}$ & 7.6 & 18.6 & 19.1 & 19.4 & 121.5 & 12.6 & 82.2 & 45300 \\
\hline 14 & $\mathrm{~F}$ & 7.6 & 19.1 & 19.5 & 19.2 & 120.5 & 13.2 & 85.8 & $\dagger$ \\
\hline 15 & $\mathrm{~F}$ & 9.2 & 21.9 & 21.6 & 22.0 & 131.0 & 12.8 & 79.9 & 7600 \\
\hline 16 & $\mathrm{~F}$ & 4.8 & 15.1 & 15.5 & 14.8 & 101.5 & 14.7 & 96.5 & 228000 \\
\hline 17 & $\mathrm{M}$ & 13.2 & 24.6 & 25.1 & 25.1 & 134.0 & 13.7 & 84.9 & 16800 \\
\hline 18 & $\mathrm{M}$ & 15.0 & 33.5 & 33.2 & 32.8 & 147.5 & 15.4 & 89.4 & 25800 \\
\hline 19 & $\mathrm{M}$ & 3.7 & 14.2 & 14.3 & 14.3 & 99.0 & 14.5 & 93.9 & 42800 \\
\hline Mean & & 9.4 & 24.1 & 24.1 & 24.4 & 128.5 & 14.1 & 86.3 & 91800 \\
\hline SEM & & 0.9 & 2.0 & 1.9 & 2.1 & 4.5 & 0.3 & 1.3 & 43100 \\
\hline
\end{tabular}

* Weight relative to the mean weight for height according to the National Committee for Health Statistics standards.

$\dagger$ Missing value because of staining problems; estimated to be 45000 by a parasite per high power field count.

outpatient clinic with a malaria crisis were candidates to be included in the study. They came for treatment within a day or two after the onset of malaria. Malaria was defined as a disease characterized by an axillary temperature higher than $37.5^{\circ} \mathrm{C}$ and a parasitemia higher than 5000 parasites $/ \mu \mathrm{L}$ (14). For 14 children, this episode was their first malaria crisis during the year of the study, whereas for the five others, it was their 2 nd to 5 th episode. The treatment was started with an initial dose of 100 to $600 \mathrm{mg}$ of chloroquine (depending on body weight), then three doses of 75 to $300 \mathrm{mg}$ over $2 \mathrm{~d}$. The children also received antipyretics [either paracetamol (initial dose 125 to $500 \mathrm{mg}$ ) or aspirin (initial dose 300 to $600 \mathrm{mg}$ )]. Within $30 \mathrm{~min}$ after the administration of the treatment, each child's REE was measured over $30 \mathrm{~min}$ in the postabsorptive state by indirect calorimetry using a ventilated hood system $(15,16)$. This test was called test A. A detailed description of the method used in Keneba has been reported elsewhere (17). Axillary temperature was measured by a mercury thermometer before and after the REE measurement. Heart rate was estimated by counting the pulse over $30 \mathrm{~s}$ during the REE measurement. The ambient temperature was kept in a comfortable zone to avoid the occurrence of shivering or the induction of sweating.

Three to $4 \mathrm{~d}$ after the therapy onset (test B), REE and anthropometry measurements were again carried out in the fasting child in the same environmental conditions. If the axillary temperature was higher than $37.5^{\circ} \mathrm{C}$ during test $\mathrm{B}$ or if the child presented any complications, he or she was then excluded from the study. On this basis, one child was excluded. A last REE and anthropometric measurement (test C) was carried out 14 to 21 $\mathrm{d}$ (mean duration $16.6 \pm 0.6 \mathrm{~d}$ ) after the treatment onset.

Analysis of results. The results are expressed as mean \pm SEM. Statistical differences were assessed by using a paired $t$ test when comparing two situations or an analysis of variance of repeated measurements when comparing more than two tests. The level of significance was chosen as $p<0.05$.

\section{RESULTS}

Anthropometry, temperature and heart rate. As shown in Table 1 , body weight, height, BMI, fat-free mass, and the relative body fat of the children were not significantly different among the three experimental situations, $\mathrm{A}, \mathrm{B}$, and $\mathrm{C}$.

In test $\mathrm{A}$, axillary temperature measured just before $\mathrm{REE}$ measurement was $39.4 \pm 0.2^{\circ} \mathrm{C}$; it decreased slightly to $39.0 \pm$ $0.2^{\circ} \mathrm{C}$ at the end of REE measurement $(p<0.05)$. The mean of these two values was used as the axillary temperature $(\mathrm{T})$ during test $\mathrm{A}\left(39.2 \pm 0.1^{\circ} \mathrm{C}\right)$. In test $\mathrm{B}$, axillary temperature decreased to $36.6 \pm 0.1^{\circ} \mathrm{C}$, a highly significant change $(p<0.0001)$. In test $\mathrm{C}$, axillary temperature was $36.7 \pm 0.1^{\circ} \mathrm{C}$, a value similar to that observed in test B (Table 2).

In test $A$, heart rate was $121 \pm 4 \mathrm{~min}^{-1}$; it decreased to $84 \pm$ $4 \min ^{-1}(p<0.0001)$ in test B and averaged $85 \pm 4$ min $^{-1}$ in test $\mathrm{C}$, a value similar to that of test $\mathrm{B}$.

$R E E$ and $R Q$. REE was positively correlated with budy weight $(r=0.948, p<0.0001 ; r=0.924, p<0.0001$; and $r=0.895, p$ $<0.0001$, respectively, in test A, B, and C). For the analysis of the results, the values of REE were normalized for body weight and expressed in $\mathrm{kJ} / \mathrm{kg} \cdot \mathrm{d}$. REE averaged $223 \pm 10,174 \pm 8$, and $169 \pm 8 \mathrm{~kJ} / \mathrm{kg} \cdot \mathrm{d}$ in tests $\mathrm{A}, \mathrm{B}$, and C, respectively (Table 2 and Fig. 1).

REE in test A was $19.2 \pm 1.9 \%(p<0.0001)$ higher than the basal metabolic rate predicted by the Schofield equation (18) (predicted basal metabolic rate $=187 \pm 8 \mathrm{~kJ} / \mathrm{kg} \cdot \mathrm{d}$ ), whereas $\mathrm{REE}$ in test $\mathrm{B}$ and in test $\mathrm{C}$ were $7.6 \pm 1.6 \%(p<0.0005)$ and $10.0 \pm 1.5 \%(p<0.0001)$ lower than the predicted values, respectively.

REE in test A was $29.5 \pm 2.6 \%(p<0.0001)$ higher than REE in test $\mathrm{B}$ and $32.8 \pm 1.7 \%(p<0.0001)$ higher than REE in test $C$. However, the values of REE in tests $B$ and $C$ were not significantly different from each other (Fig. 1). Expression of the REE results per unit fat-free mass or body surface area did not change the degree of significance among tests $\mathrm{A}, \mathrm{B}$, and $\mathrm{C}$. In test $\mathrm{A}$, heart rate was positively correlated with $\operatorname{REE}(r=0.576$, $p<0.01$ ).

The parasitemia measured at the study onset (mean value $=$ 91800 parasites $/ \mu \mathrm{L}$, ranging from 7600 to 818000 parasites $/ \mu \mathrm{L}$ ) did not show any correlation with REE, axillary temperature, or heart rate.

RQ in test $\mathrm{A}(0.804 \pm 0.013)$ was significantly lower $(p<$ 
Table 2. Axillary temperature (T), REE, and $R Q$ in children measured in tests $A, B$, and $C$

\begin{tabular}{|c|c|c|c|c|c|c|c|c|c|}
\hline \multirow[b]{2}{*}{ Subject } & \multicolumn{3}{|c|}{ Test A (d 0) } & \multicolumn{3}{|c|}{ Test B (d 3-4) } & \multicolumn{3}{|c|}{ Test C (d 14-21) } \\
\hline & $\begin{array}{c}\mathrm{T} \\
\left({ }^{\circ} \mathrm{C}\right)\end{array}$ & $\begin{array}{c}\mathrm{REE} \\
(\mathrm{kJ} / \mathrm{kg} \cdot \mathrm{d})\end{array}$ & $\mathrm{RQ}$ & $\begin{array}{c}\mathrm{T} \\
\left({ }^{\circ} \mathrm{C}\right)\end{array}$ & $\begin{array}{c}\mathrm{REE} \\
(\mathrm{kJ} / \mathrm{kg} \cdot \mathrm{d})\end{array}$ & $\mathrm{RQ}$ & $\begin{array}{c}\mathrm{T} \\
\left({ }^{\circ} \mathrm{C}\right)\end{array}$ & $\begin{array}{c}\text { REE } \\
(\mathrm{kJ} / \mathrm{kg} \cdot \mathrm{d})\end{array}$ & $\mathrm{RQ}$ \\
\hline 1 & 39.6 & 209 & 0.775 & 36.6 & 158 & 0.802 & 36.7 & 155 & 0.968 \\
\hline 2 & 38.9 & 203 & 0.825 & 36.8 & 174 & 0.824 & 36.8 & 150 & 0.974 \\
\hline 3 & 39.3 & 189 & 0.796 & 35.9 & 121 & 0.896 & 37.2 & 137 & 0.901 \\
\hline 4 & 38.7 & 165 & 0.734 & 37.0 & 124 & 0.808 & 36.9 & 122 & 0.833 \\
\hline 5 & 39.8 & 317 & 0.782 & 36.0 & 270 & 0.844 & 37.2 & 264 & 0.824 \\
\hline 6 & 40.2 & 185 & 0.971 & 36.3 & 134 & 0.832 & 36.7 & 142 & 0.902 \\
\hline 7 & 37.8 & 222 & 0.765 & 36.3 & 179 & 0.872 & 37.3 & 184 & 0.870 \\
\hline 8 & 38.1 & 204 & 0.785 & 36.5 & 175 & 0.901 & 37.0 & 174 & 0.860 \\
\hline 9 & 39.7 & 271 & 0.809 & 36.5 & 199 & 0.844 & 36.7 & 187 & 0.895 \\
\hline 10 & 39.3 & 245 & 0.914 & 37.2 & 214 & 0.819 & 36.1 & 183 & 0.813 \\
\hline 11 & 39.5 & 209 & 0.817 & 36.9 & 170 & 0.868 & 36.8 & 164 & 0.874 \\
\hline 12 & 39.4 & 180 & 0.773 & 37.0 & 150 & 0.806 & 35.9 & 132 & 0.876 \\
\hline 13 & 39.4 & 236 & 0.815 & 35.9 & 180 & 0.871 & 35.6 & 166 & 0.912 \\
\hline 14 & 38.9 & 222 & 0.785 & 36.9 & 182 & 0.827 & 36.5 & 171 & 0.918 \\
\hline 15 & 39.3 & 209 & 0.789 & 36.5 & 166 & 0.806 & 36.0 & 158 & 0.876 \\
\hline 16 & 39.2 & 251 & 0.742 & 37.2 & 190 & 0.818 & 36.5 & 189 & 0.839 \\
\hline 17 & 39.0 & 209 & 0.792 & 36.5 & 149 & 0.819 & 36.7 & 156 & 0.824 \\
\hline 18 & 39.1 & 194 & 0.773 & 36.5 & 142 & 0.818 & 36.5 & 140 & 0.872 \\
\hline 19 & 39.7 & 319 & 0.825 & 36.5 & 220 & 0.832 & 37.3 & 232 & 0.923 \\
\hline Mean & 39.2 & 223 & 0.804 & 36.6 & 174 & 0.837 & 36.7 & 169 & 0.882 \\
\hline SEM & 0.1 & 10 & 0.013 & 0.1 & 8 & 0.007 & 0.1 & 8 & 0.010 \\
\hline
\end{tabular}

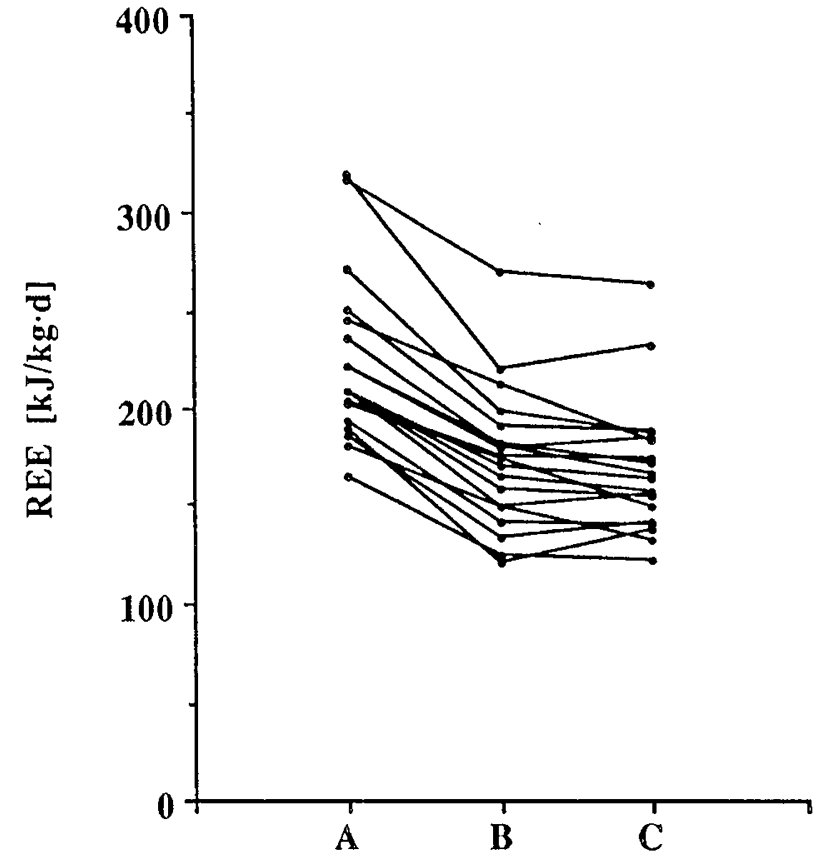

TESTS

Fig. 1. Individual REE values in tests $A, B$, and $C$.

$0.05)$ than in test $\mathrm{B}(0.837 \pm 0.007)$; the latter was lower $(p<$ $0.005)$ than in test $\mathrm{C}(0.882 \pm 0.010)$ (Table 2$)$.

Relationship between REE and axillary temperature. The individual difference in temperature between tests $\mathrm{A}$ and $\mathrm{B}(\Delta \mathrm{T})$ was positively correlated with the difference in REE between these two tests $(r=0.515, p<0.05)$. When this difference was expressed relative to the value of REE in test $B$ (considered as a baseline), this relative difference ( $\triangle \mathrm{REE}$ ) was also correlated with $\Delta \mathrm{T}(r=0.457, p<0.05)$ (Fig. 2). The slope of the regression line $\left(6.9 \%\right.$ change in $\left.\mathrm{REE} /{ }^{\circ} \mathrm{C}\right)$ represents an estimate of the increase in $\mathrm{REE} /{ }^{\circ} \mathrm{C}$ of fever. The intercept of the regression line described above at $\Delta \mathrm{T}=0$ gives a value of a change in REE of $11.5 \%$.

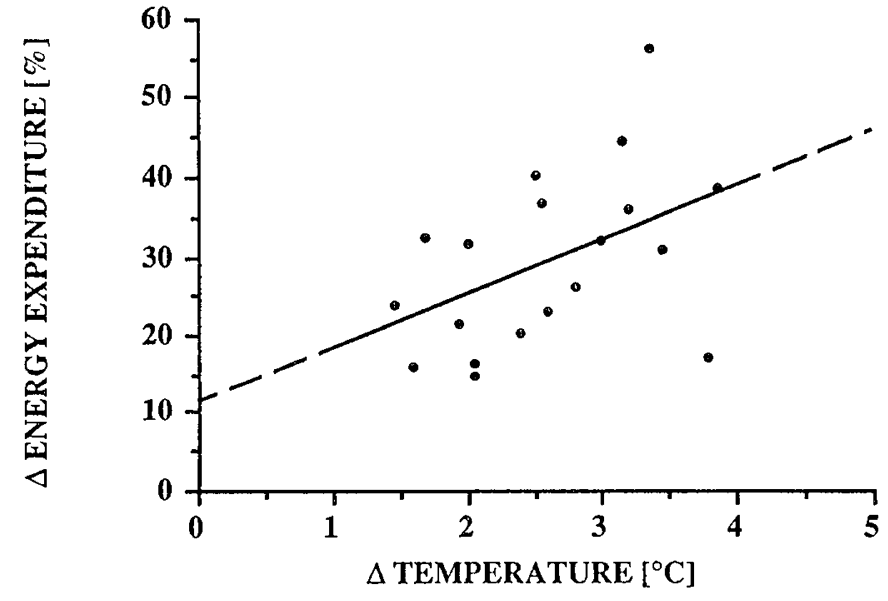

Fig. 2. Correlation between the difference in temperature $(T)$ between tests $\mathrm{A}$ and $\mathrm{B}[\Delta \mathrm{T}=\mathrm{T}(\mathrm{A})-\mathrm{T}(\mathrm{B})]$ and the relative augmentation in REE $(\triangle \operatorname{REE}=\{[\operatorname{REE}(\mathrm{A})-\operatorname{REE}(\mathrm{B})] / \operatorname{REE~B}\} \cdot 100)(r=0.457, p<0.05)$.

This value can be considered as the increase in REE during the acute episode of malaria that is not related to fever.

Another way to assess the global energy cost of fever is to calculate for each child the increase in $\mathrm{REE} /{ }^{\circ} \mathrm{C}$ of fever (i.e. $\triangle \mathrm{REE} / \Delta \mathrm{T}$ ) between test $\mathrm{A}$ and $\mathrm{B}$; this approach gives an average "cost of fever" of $11.7 \%$ of $\mathrm{REE} /{ }^{\circ} \mathrm{C}$, i.e. a $29.5 \pm 2.6 \%$ rise in REE for a change in temperature of $2.6 \pm 0.2^{\circ} \mathrm{C}$. The rise of $\mathrm{REE} /{ }^{\circ} \mathrm{C}$ of fever was positively correlated with BMI ( $r=0.573$, $p<0.05)$ and with the weight for height expressed as a percentage of the expected values (19) $(r=0.539, p<0.05$; Fig. 3).

\section{DISCUSSION}

The deleterious impact of malaria on growth in children (13 ) is probably explained by the occurrence of negative energy and nitrogen balances (20). The negative energy balance stems from the diminution of food intake induced by anorexia and from the hypermetabolism due to the acute episode of malaria. In the present study, the changes in energy metabolism were investigated without attempting to delineate the effect of malaria 


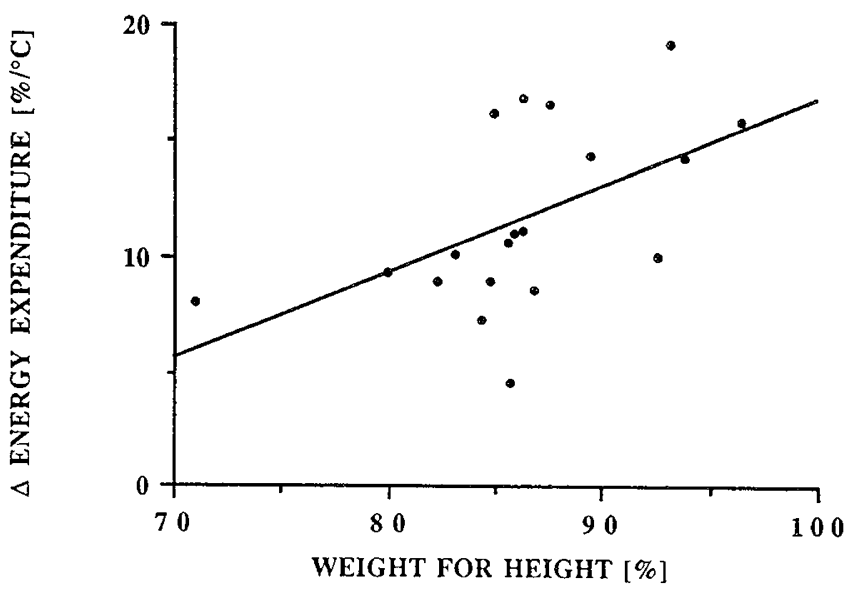

Fig. 3. Correlation between the children's percentage of weight for height (according to the National Committee for Health Statistics standards) and the relative augmentation in REE per degree of fever ( $\triangle \mathrm{REE} /$ $\Delta \mathrm{T})(r=0.539, p<0.05)$.

on food intake. Therefore, it was not possible to assess the degree of energy imbalance caused by the illness.

Anthropometry. By using the National Committee for Health Statistics standards (19), the weight of the children averaged 86.3 $\pm 1.3 \%$ relative to the expected weight for height (Table 1$)$. In addition, the percentage of body fat of all the children was lower than the Fomon's standards (21). These results illustrate the poor nutritional state of these rural Gambian children.

It is interesting to note that the mean value of body weight and body composition of the children did not change significantly throughout the 14 to $21 \mathrm{~d}$ of study. The duration of the fever episode was less than $4 \mathrm{~d}$. However, most children from developing countries do not have access to immediate therapy when they suffer from malaria. Therefore, the febrile period may last longer than in this study, which can result in a weight loss (3).

$R E E$ and $R Q$. In the present study, REE measured in test $\mathrm{C}$ (14 to $21 \mathrm{~d}$ after the treatment onset, when the children had recovered from the acute episode of malaria) was $10.0 \pm 1.5 \%$ lower than the basal metabolic rate predicted from Schofield's equations (18), which confirms previous findings in adults from The Gambia (22). Even in the early recovery phase (test B, 3 to $4 \mathrm{~d}$ after the treatment onset), REE was lower than Schofield's prediction. This low metabolic rate might result from an adaptive response to the marginal nutrient intake during the rainy season, as previously shown in Gambian adults $(22,23)$ and children (24). This adaptive response appears to decrease the energy expenditure in individuals subjected to a chronic lack of food.

The REE due to the acute malaria episode was $29.5 \pm 2.6 \%$ greater than that observed in the early recovery period (test B). Eccles et al. (4), however, showed a decrease in the sleeping energy expenditure of two children during the acute phase of malaria after correcting for the effect of body temperature. The reasons for these discrepant results remain unclear. An interesting observation is the early normalization in REE after the acute episode of malaria that parallels the return to a normal axillary temperature. As emphasized by McGregor (20), the situation may be quite different when the infection is not immediately treated; it is likely that energy expenditure remains elevated as long as fever is present. Inasmuch as the acute phase of malaria is characterized by anorexia, food intake is reduced. Although REE is elevated, energy expenditure due to physical activity is reduced in these children, who usually remain supine during the acute episode. If the child does not eat when febrile, the energy deficit due to malaria can be estimated to be $130 \%$ of his usual REE. For example, a 5-yr-old fasting child would expend about $5000 \mathrm{~kJ} / \mathrm{d}$ during an acute episode of malaria, corresponding to a weight loss of 250 to $300 \mathrm{~g} / \mathrm{d}$ (15 to $20 \mathrm{~g} / \mathrm{kg} \cdot \mathrm{d}$ ) (25).
During the acute phase, it was observed that the RQ was lower than during the early recovery phase, and then it increased again in test $\mathrm{C}$. This could be explained by the fact that at the time of the first measurement the child was in postabsorptive conditions because of the anorexia related to the infection; it is likely that the child uses endogenous body fat mainly for covering his or her energy expenditure. The increase in RQ in the late recovery phase is in keeping with resuming food intake and shows that there is an increase in carbohydrate oxidation.

Relationship between fever and REE. As shown in Figure 2, the relative increase in REE was significantly correlated with the increase in axillary temperature $(r=0.457, p<0.05)$. The fraction of the increase in REE explained by fever is defined by the slope of the regression line $\left(6.9 \% / 1^{\circ} \mathrm{C}\right)$, whereas the intercept at $0^{\circ} \mathrm{C}$ change in temperature can be considered as the increase in REE that is independent of fever. This corresponds to an elevation of REE of $11.5 \%$ attributed to factors other than fever, such as the increased protein turnover (26). The anemia usually observed with malaria is accompanied by an increase in cardiac output to maintain oxygen delivery to the tissues; this is accompanied by a rise in cardiac oxygen consumption.

Another way of calculating the rise in energy expenditure related to fever is to divide the individual increase in REE by the individual increase in temperature, thus assuming that all of the rise in REE can be attributed to fever. With this approach, the caloric cost of fever is $11.7 \%$ per unit rise $\left({ }^{\circ} \mathrm{C}\right)$ in axillary temperature. This value is similar to that calculated by Du Bois (8).

The fact that the increase in REE for each degree of increase in temperature was positively correlated to BMI and to the percentage of the expected weight for height (Fig. 3) indicates that a child with an impaired nutritional state responds with a smaller hypermetabolism than a better nourished child for the same degree of fever. This could be explained by an adaptive mechanism to the marginal nutritional status of the child or by lower immune and metabolic responses to the infection process in the presence of malnutrition $(20,27)$. This observation may have important implications for saving energy in a child whose nutritional status is compromised.

In conclusion, in Gambian children suffering from an acute episode of malaria, REE was increased by $30 \%$. There was a prompt return of REE to baseline values within $4 \mathrm{~d}$ after onset of therapy. These data show that the important hypermetabolism induced by the acute phase of the disease is abolished by effective therapy. When such therapy is not available, the hypermetabolism associated with anorexia may aggravate energy deficit. These observations emphasize the need to begin the treatment of malaria without any delay to reduce the duration of the severe hypermetabolism associated with the acute phase of the disease.

Acknowledgments. The authors thank the children who kindly took part in the study, as well as their parents for their cooperation. We also thank the field workers Musa Jarjou, Yaya Ceesay, Fatou Bah, Michael Mendy, and Faks Manka and the lab technicians Karamo Camara and Momodou Darboe for their work. The help of Olivier Pasche, and Drs. Andrew Prentice, Beat Schürch, Brian Greenwood, and Jean-Leopold Micheli was particularly appreciated.

\section{REFERENCES}

1. Martorell R, Habicht J-P 1986 Growth in early childhood in developing countries. In: Falkner F, Tanner JM (eds) Human Growth, Vol 3. Plenum Press, New York, pp 241-262

2. Nabarro D, Howard P, Cassel C, Pant M, Wijga A, Padfield N 1988 The importance of infections and environmental factors as possible determinants of growth retardation in children. In: Waterlow J (ed) Linear Growth Retardation in Less Developed Countries. Nestle Nutrition Workshop Series. Raven Press, New York, pp 165-183

3. Rowland MGM, Cole TJ, Whitehead R 1977 A quantitative study into the role of infection in determinating nutritional status in Gambian village children. Br J Nutr 37:441-450 
4. Eccles M, Cole TJ, Whitehead R 1989 Factors influencing sleeping metabolic rate in infants. Eur J Clin Nutr 43:485-492

5. Duggan MB, Alwar J, Milner RDG 1986 The nutritional cost of measles in Africa. Arch Dis Child 61:61-66

6. Duggan MB, Milner RDG 1986 The maintenance energy requirement for children: an estimate based on a study of children with infection associated underfeeding. Am J Clin Nutr 43:870-878

7. Duggan MB, Milner RDG 1986 Energy cost of measles infection. Arch Dis Child 61:436-439

8. Du Bois EF 1921 The basal metabolism in fever. JAMA 77:352-355

9. Eccles M 1989 A prospective study of the effects of frequent infection on the energy metabolism of Gambian infants. Thesis, Newcastle University $\mathrm{Li}$ brary, No 08707248 7, Newcastle, UK

10. Prentice AM, Prentice A 1988 Reproduction against the odds. New Sci 14:4246

11. McGregor IA, Rahman AK, Thomson AM, Billewicz WZ, Thompson B 1970 The health of young children in a West African (Gambian) village. Trans $R$ Soc Trop Med Hyg 64:48-77

12. Weiner JS, Lourie JA 1969 Human Biology: A Guide to Field Methods. Blackwell Scientific Publications, Oxford, UK

13. Brook CGD 1971 Determination of body composition of children from skin fold measurements. Arch Dis Child 46:182-184

14. WHO Secretariat for the Coordination of Malaria Training in Asia and the Pacific 1983 Aids to Human Malaria Diagnosis. World Health Organization, Geneva

15. Jéquier E 1981 Long-term measurement of energy expenditure in man: direct or indirect calorimetry? In: Björntorp P, Cairellaz M, Howard AN (eds) Recent Advances in Obesity Research III. Libbey J, London, pp 130-135
16. Jéquier E 1987 Measurement of energy expenditure in clinical nutrition assessment. J Parenter Enteral Nutr 1 1:86S-89S

17. Charbonnier A, Jones CDR, Schutz Y, Murgatroyd PR, Whitehead R, Jéquier E, Spinnler G 1990 A whole body transportable indirect calorimeter for human use in the tropics. Eur J Clin Nutr 44:725-731

18. Schofield WN 1985 Predicting basal metabolic rate, new standards and review of previous work. Hum Nutr Clin Nutr 39C(suppl 1):5-41

19. National Committee for Health Statistics 1976 Growth Charts. United States Department of Health, Education and Welfare, Public Health Service, Health Resources Administration, Rockville, MD

20. McGregor IA 1982 Malaria: nutritional implications. Rev Infect Dis 4:798804

21. Fomon S, Haschke F, Ziegler EE, Nelson SE 1982 Body composition of reference children from birth to age 10 years. Am J Clin Nutr 35:1169-1175

22. Minghelli G, Schutz Y, Charbonnier A, Whitehead R, Jéquier E 1990 Twentyfour-hour energy expenditure and basal metabolic rate measured in a wholebody indirect calorimeter in Gambian men. Am J Clin Nutr 51:563-570

23. Minghelli G, Schutz Y, Whitehead R, Jéquier E 1991 Seasonal changes in $24-\mathrm{h}$ and basal energy expenditure in rural Gambian men as measured in a respiratory chamber. Am J Clin Nutr 53:14-20

24. Vasquez-Velasquez L, Prentice AM, Coward WA 1988 Energy expenditure and physical activity in malnourished Gambian infants. Proc Nutr Soc 47:233-239

25. Spady DW, Payne RR, Picou D, Waterlow JC 1976 Energy balance during recovery from malnutrition. Am J Clin Nutr 29:1073-1088

26. Tomkins AM, Garlick PJ, Fern E, Waterlow JC 1984 The effect of acute malaria on nitrogen metabolism in young children. Proc Nutr Soc 43:138A

27. Targett GAT 1981 Malnutrition and immunity to protozoan parasites. In Isliker H, Schürch B (eds) The Impact of Malnutrition on Immune Defence in Parasitic Infestation. Hans Huber Publishers, Bern, Switzerland, pp 157181 